\title{
PEMBERDAYAAN MASYARAKAT DALAM PEMANFAATAN LIMBAH LAMPU HEMAT ENERGI (LHE) SEBAGAI ALTERNATIF LAMPU EMERGENCY DENGAN TEKNIK JOULE THIEF
}

\author{
Junaidi*, Agus Riyanto, Gurum Ahmad Pauzi, dan Arif Surtono \\ Jurusan Fisika, Fakultas Matematika dan Ilmu Pengetahuan Alam, Universitas Lampung, Bandar Lampung \\ Jl. Prof. Sumantri Brojonegoro No.1 Bandar Lampung 35145 \\ Penulis Korespodensi : junaidi.1982@fmipa.unila.ac.id
}

\begin{abstract}
Abstrak
Pengabdian ini merupakan bentuk kegiatan pemberdayaan masyarakat dalam pemafaatan limbah lampu hemat energi (LHE) untuk pembuatan lampu emergency. Pembuatan lampu emergency dilakukan dengan metode JouleThief. Metode ini mampu meningkatkan daya listrik rendah dari sumber baterai 1,5 volt menjadi arus bolak-balik AC yang dapat menyalakan lampu LED. Peserta dalam kegiatan pengabdian kepada masyarakat ini adalah sekitar 32 orang. Setiap peserta pengabdian dibina tentang proses pemanfaatan limbah lampu LHE yang sudah tidak terpakai agar menjadi barang siap guna dan memiliki nilai jual ekonomis. Komponen yang digunakan dalam pembuatan lampu emergency semuanya diperoleh dari komponen dari bekas lampu LHE. Dengan kegiatan ini diharapkan masyarakat mitra menjadi paham tentang bagaimana memanfaatkan limbah yang sulit terurai menjadi barang siap jual. Hasil pengabdian menunjukkan bahwa pencapaian TIK sebelum kegiatan pengabdian pembuatan lampu emergency dengan teknik Joule Thief adalah 35,63\%. Pencapaian TIK setelah kegiatan pengabdian pembuatan emergency adalah 80,94\%. Dari hasil tersebut, terjadi peningkatan untuk masing-masing pencapaian TIK dengan rata-rata sebesar 45,31\%.
\end{abstract}

Kata kunci: Lampu Emergency, Joule Thief, Hemat Energi, Limbah

\section{Pendahuluan}

Energi listrik merupakan kebutuhan pokok bagi seluruh penduduk di dunia khususnya Indonesia. Kebijakan Pemerintah tentang penyesesuaian tariff dasar listrik (TDL) mulai tanggal 1 Januari 2017 menyatakan bahwa TDL untuk pelanggan. Kenaikan tarif listrik tersebut tentunya sangat memberatkan masyarakat Indonesia pada umumnya dan masyarakat di Desa Sakal Kecamatan Merbau Mataram pada khususnya. Hal ini dikarenakan sebagian besar masyarakat yang tinggal daerah tersebut adalah pelanggan listrik 900 watt (PERMEN ESDM, 2010).

Desa Sakal adalah salah satu desa yang memiliki luas sebesar 4,258 Ha yang berada di Kecamatan Merbau Mataram Kabupaten Lampung Selatan. Mayoritas mata pencaharian penduduknya adalah petani dan buruh harian lepas. Terbatasnya jumlah pasokan energi listrik, khususnya pada jam pemakaian tinggi (malam hari) menyebabkan seringnya terjadi pemadaman listrik secara bergilir oleh PLN. Pemadaman listrik tersebut menimbulkan dampak terganggunya aktivitas masyarakat di malam hari yang mengandalkan lampu penerangan (Arfiansyah dkk., 2012). Permasalahan utama yang dihadapi oleh masyarakat di desa Sakal Kecamatan Merbau Mataram Kabupaten Lampung Selatan adalah seringnya terjadi pemadaman listrik di malam hari. Kondisi ini menyebabkan lokasi atau desa manjadi gelap dengan mengandalkan lampu dari lilin atau senter.

Tingkat pendidikan masyarakat Desa Sakal di Kecamatan Merbau Mataram Kabupaten Lampung Selatan masih tergolong rendah. Hal ini dilihat dari mayoritas mata pencaharian penduduk sebagai petani dan buruh harian lepas. Kondisi inilah yang melatarbelakangi perlunya pembinaan masyarakat tentang listrik khususnya pemanfaatan limbah lampu hemat energi (LHE). Salah satu upaya yang dapat dilakukan untuk mengantisipasi pemadaman listrik adalah dengan lampu emergency menggunakan lampu LED (Fithri, 2014). LED mengkonsumsi daya jauh lebih kecil dibandingkan dengan lampu fluorescent atau CFL atau lampu Neon. LED menggunakan listrik yang kecil, dengan efisiensi energi diperkirakan $80-90 \%$ 
jika dibandingkan dengan sistem pencahayaan lampu CFL dan bola lampu konvensional. Sekitar $80 \%$ dari energi listrik diubah menjadi cahaya, sedangkan $20 \%$ hilang dan diubah menjadi panas. Selain itu, lampu LED menggunakan tegangan yang lebih rendah dibandingkan lampu CFL (Schubert, 2006). Lampu LED 5 watt memiliki cahaya yang sama terangnya dengan lampu CFL sebesar 13 watt dan lampu LED 13 watt memiliki cahaya yang sama terangnya dengan lampu CFL sebesar 15 watt (Suhadi, 2014).

Selain sangat efisien dan hemat energi listrik, Lampu LED juga tidak mengandung bahan material berbahaya bagi kesehatan dan lingkungan, lampu CFL mengandung bahan atau zat Mercury. Lampu LED menghasilkan emisi atau gas buang berupa karbondiosida sebesar 202,95 kg setiap tahunnya, sedangkan lampu CFL mengahasilkan karbondioksida sebesar $472,95 \mathrm{~kg}$ per tahun. Terlihat jelas jika lampu LED lebih ramah lingkungan dibandingkan CFL (Ade dkk., 2013). Dari Permasalahan tersebut maka diperlukan solusi anternatif bagi masyarakat ketika terjadi pemadalam listrik. Salah satu solusi alternatif adalah pemanfaatan limbah LHE menjadi produk siap pakai atau bahkan bernilai ekonomis berupa lampu emergency.

Adapun tujuan dari kegiatan pengabdian ini secara terperinci adalah mengimplementasikan ilmu pengetahuan dan teknologi kepada masyarakat melalui pengabdian, melatih masyarakat mitra untuk belajar memanfaatkan limbah LHE agar menjadi barang layak pakai atau bernilai ekonomis; dan memanfaatkan limbah LHE menjadi lampu emergency sebagai sumber penerangan ketika terjadi pemadaman listrik.

Manfaat dari hasil pelatihan dalam bentuk pemberdayaan masyarakat melalui program pengabdian kepada masyarakat adalah sebagai berikut: (i) mengurangi dampak pencemaran lingkungan yang diakibatkan oleh limbah LHE yang tidak digunakan, (ii) Terjadinya transfer ilmu pengetahuan kepada masyarakat melaui program PKM, (iii) Masyarakat mitra menjadi lebih paham dalam pemanfaatan limbah LHE menjadi barang layak pakai dan bernilai ekonomis, dan (iv) Setiap warga masyarakat memahami tentang fungsi dan kegunaan dar lampu LHE.

\section{Bahan dan Metode}

A. Bahan-bahan yang digunakan

Bahan-bahan yang digunakan dalam pelaksanaan kegiatan pengabdian kepada masyarakat adalah: limbah lampu hemat energi (LHE), limbah charger, fitting lampu, lampu LHE, saklar, baterai $1,5 \mathrm{~V}$, solder, multimeter, dan elektronic toolkits.

\section{B. Prosedur kerja untuk mendukung realisasi metode yang ditawarkan}

Prosedur kerja untuk mendukung realisasi metode yang ditawarkan dalam pelaksanaan kegiatan pengabdian kepada masyarakat dimulai dengan melakukan survei ke lapangan. Selanjutnya, merencanakan materi yang akan diberikan, menyiapkan peralatan dan bahan-bahan untuk pelatihan pembuatan lampu emergency dari limbah lampu LHE, merencakan pembagian kerja diantara tim pelaksana, dan mengadakan kesepakatan waktu kegiatan dengan masyarakat dilingkungan Desa Sakal Kec. Merbau Mataram Kab. Lampung Selatan.

Tahapan dalam praktik pembuatan lampu emergency adalah sebagai berikut: Pertama, pengenalan komponen yang ada pada bekas lampu LHE. Kemudian tahap pencopoton beberapa komponen yang akan digunakan untuk membuat lampu emergency. dilakukan untuk melatih peserta pelatihan membuat lampu LED. Contohnya lampu LHE bekas yang sudah tidak digunakan lagi seperti terlihat pada Gambar 1.

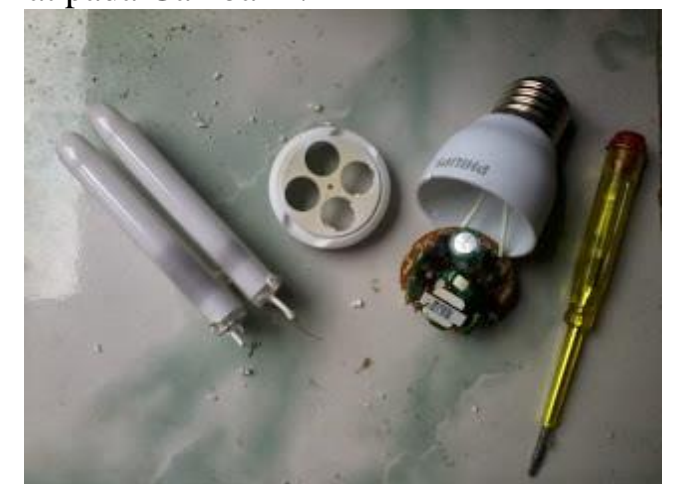

Gambar 1. Limbah Lampu LHE yang sudah rusak

Ketiga, membuka komponen-komponen yang akan dipakai untuk pembuatan lampu emergency, seperti: trafo ferit, resistor, dan transistor seperti pada Gambar 2(a-d). Keempat, proses perakitan lampu emergency dari limbah LHE sesuai dengan diagram rangkaian pada Gambar 2(e-f). 


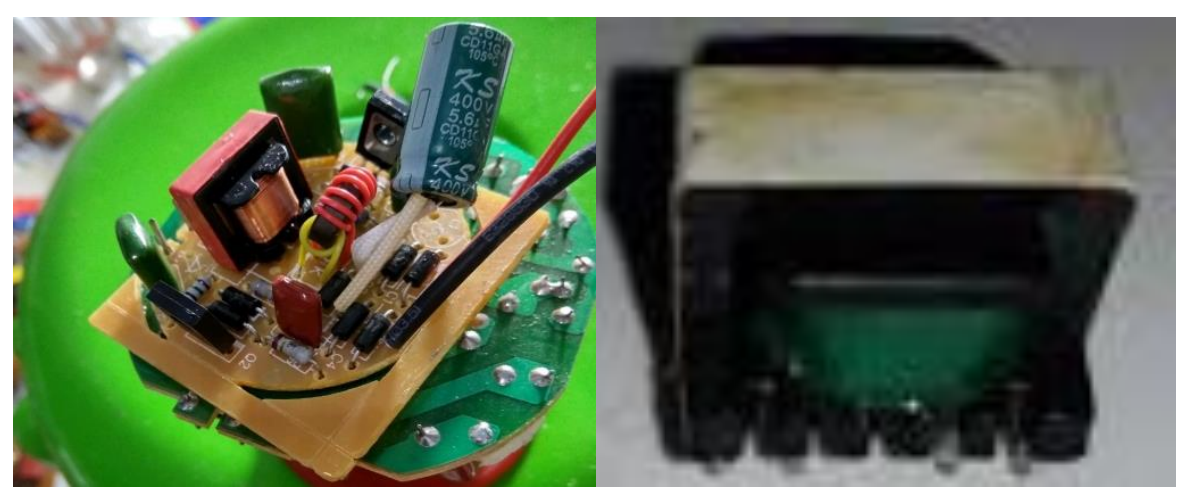

(a)

(b)

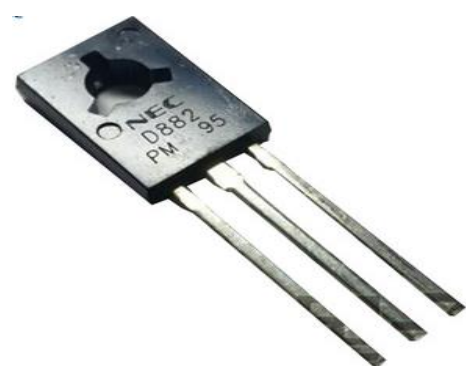

(c)

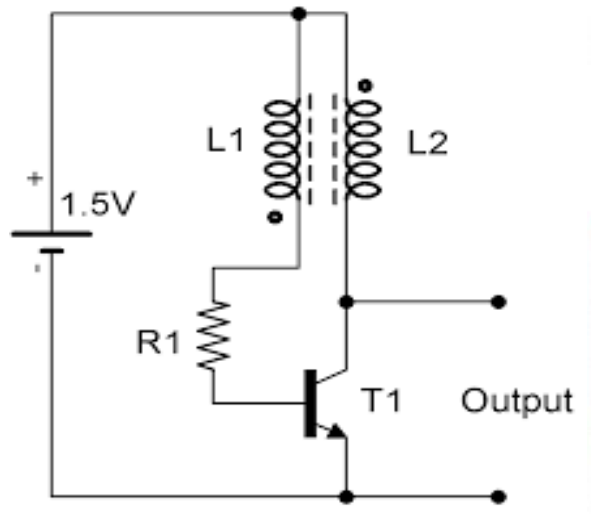

(e)

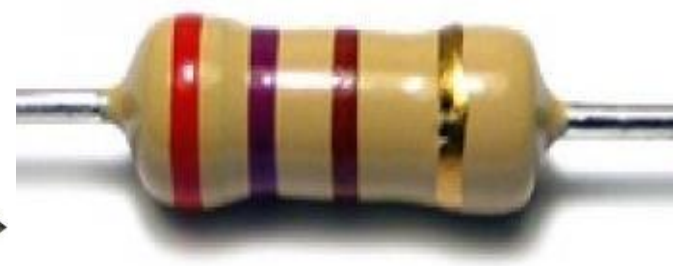

(d)

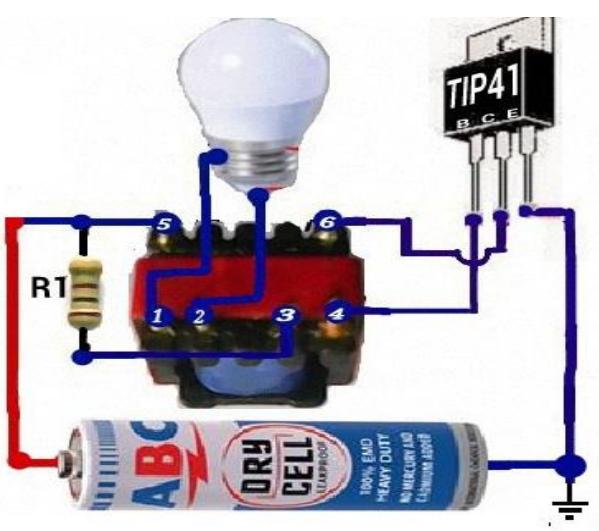

(f)

Gambar 2. (a) mesin LHE, (b) trafo ferit, (c) transistor, (d) resistor, (e) rangkaian lampu emergency dan (f) tata letak komponen lampu emergency

Pada tahapan ini semua komponen digabung menjadi satu menjadi lampu emergency. Rangkaian kemudian dimasukkan ke fitting lampu seperti terlihat pada Gambar 3.

Gambar 3 menunjukkan bahwa, lampu emergancy yang dibuat dari limbah lampu LHE atau charger HP memiliki bentuk dan ukuran yang baik. Lampu ini dapat dipergunakan sebagai alternatif pengganti lilin atau lampu penerangan ketika terjadi pemadaman listrik. Lampu ini juga dapat dipergunakan di daerah-daerah terpencil yang belum terjangkau dengan aliran listrik dari PLN.

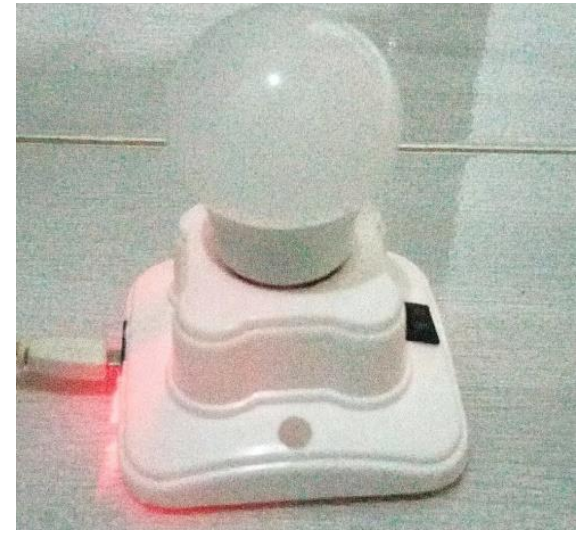

Gambar 3. Rangkain akhir lampu emergency 


\section{Hasil dan Pembahasan}

Hasil kegiatan pengbdian kepada masyarakat tentang pembuatan lampu rumah tangga ini dapat diketahui berdasarkan hasil evaluasi yang telah dilaksanakan melalui pre test dan post test. dalam kegiatan yang dilaksanakan di Dusun Sakal Desa Tanjung Baru Kecamatan Merbau Mataram Kabupaten Lampung Selatan ini. Sasarannya dibatasi untuk masyarakat sejumlah 32 orang. Sebelum kegiatan dimulai dilakukan serangkaian pre test untuk mengetahui pemahaman awal peserta terhadap pertanyaan yang diajukan yang berkaiatan dengan lampu emergency dan proses pembuatannya. Pada akhir kegiatan dilakukan post test untuk mengetahui perubahan kemampuan peserta terhadap materi pengabdian yang telah diberikan. Evaluasi kegiatan dilakukan dengan pengukuran terhadap pencapaian Tujuan Instruksional Khusus (TIK) dari kegiatan yang dilaksanakan dengan parameter pengukuran berikut ini.

a. Pengetahuan umum peserta tentang listrik.

b. Pengetahuan peserta tentang LED.

c. Pengetahuan peserta tentang cara memperbaiki lampu yang rusak.

d. Pengetahuan peserta tentang pengalaman cara memperbaiki lampu yang rusak.

e. Pengetahuan peserta tentang pembuatan lampu dengan LED.

Pertanyaan pada pre test juga merupakan pertanyaan pada post test dalam rangka mermbandingkan hasil kegiatan pelatihan dengan menyusun pertanyaan sesuai dengan TIK yang ingin dicapai dalam kegiatan pengabdian ini yang dapat dilihat pada Tabel 1.

Tabel 1. Komposisi TIK pada pre test dan post test

\begin{tabular}{|c|c|c|c|c|}
\hline No & TIK & Butir soal & Jumlah soal & Prosentase \\
\hline 1 & $\begin{array}{l}\text { Mengetahui pemahaman umum } \\
\text { peserta tentang listrik }\end{array}$ & 1,2 & 2 & 20 \\
\hline 2 & $\begin{array}{l}\text { Meningkatkan pengetahuan } \\
\text { peserta tentang LED }\end{array}$ & 7 & 1 & 10 \\
\hline 3 & $\begin{array}{l}\text { Meningkatkan pengetahuan } \\
\text { peserta tentang cara memperbaiki } \\
\text { lampu yang rusak }\end{array}$ & 3,4 & 2 & 20 \\
\hline 4 & $\begin{array}{l}\text { Meningkatkan pengetahuan } \\
\text { peserta tentang pengalaman cara } \\
\text { memperbaiki lampu yang rusak }\end{array}$ & $8,9,10$ & 3 & 30 \\
\hline 5 & $\begin{array}{l}\text { Meningkatkan pengetahuan } \\
\text { peserta tentang pembuatan lampu } \\
\text { dengan LED }\end{array}$ & 5,6 & 3 & 20 \\
\hline
\end{tabular}

Tabel 1 menunjukkan butir-butir soal untuk mengukur tingkat pemahaman dari masyarakat terkait materi pelatihan yang akan diajarkan. Soal diberikan untuk mengukur tingkat pemahaman masyarakat dalam hal: (1) mengetahui pemahaman umum peserta tentang listrik, (2) meningkatkan pengetahuan peserta tentang LED, (3) meningkatkan pengetahuan peserta tentang cara memperbaiki lampu yang rusak, (4) meningkatkan pengetahuan peserta tentang pengalaman cara memperbaiki lampu yang rusak, dan (5) meningkatkan pengetahuan peserta tentang pembuatan lampu dengan LED. Butir soal dibuat secara khusus agar dapat mewakili setiap TIK yang akan dicapai dalam pembuatan lampu emergency dengan menggunakan limbah LHE dan charger HP untuk meningkatkat kreativitas dan pemahaman masyarakat dalam pengelolaan limbah yang ada di sekitar. Hasil pencapaian TIK sebelum kegiatan pengabdian dilaksanakan dapat dilihat pada Tabel 2.

Tabel 2. Hasil pencapaian TIK sebelum dan setelah kegiatan pengabdian

\begin{tabular}{|c|c|c|c|c|c|c|c|c|c|c|c|c|c|}
\hline \multirow{2}{*}{ No } & \multirow{2}{*}{ Peserta } & \multicolumn{7}{|c|}{ Hasil Pre Test Peserta } & \multicolumn{5}{|c|}{ Hasil Post Test Peserta } \\
\hline & & TIK 1 & TIK 2 & TIK 3 & TIK 4 & TIK 5 & SKOR & TIK 1 & TIK 2 & TIK 3 & TIK 4 & TIK 5 & SKOR \\
\hline 1 & Peserta 1 & 2 & 1 & 0 & 0 & 0 & 30 & 2 & 1 & 2 & 1 & 2 & 80 \\
\hline 2 & Peserta 2 & 2 & 0 & 0 & 0 & 2 & 40 & 1 & 0 & 2 & 3 & 1 & 70 \\
\hline 3 & Peserta 3 & 1 & 0 & 1 & 1 & 1 & 40 & 2 & 1 & 1 & 3 & 2 & 90 \\
\hline 4 & Peserta 4 & 0 & 1 & 2 & 0 & 0 & 30 & 1 & 1 & 2 & 2 & 2 & 80 \\
\hline 5 & Peserta 5 & 1 & 0 & 1 & 1 & 1 & 40 & 2 & 1 & 2 & 3 & 1 & 90 \\
\hline 6 & Peserta 6 & 1 & 0 & 1 & 2 & 0 & 40 & 2 & 1 & 2 & 1 & 2 & 80 \\
\hline
\end{tabular}




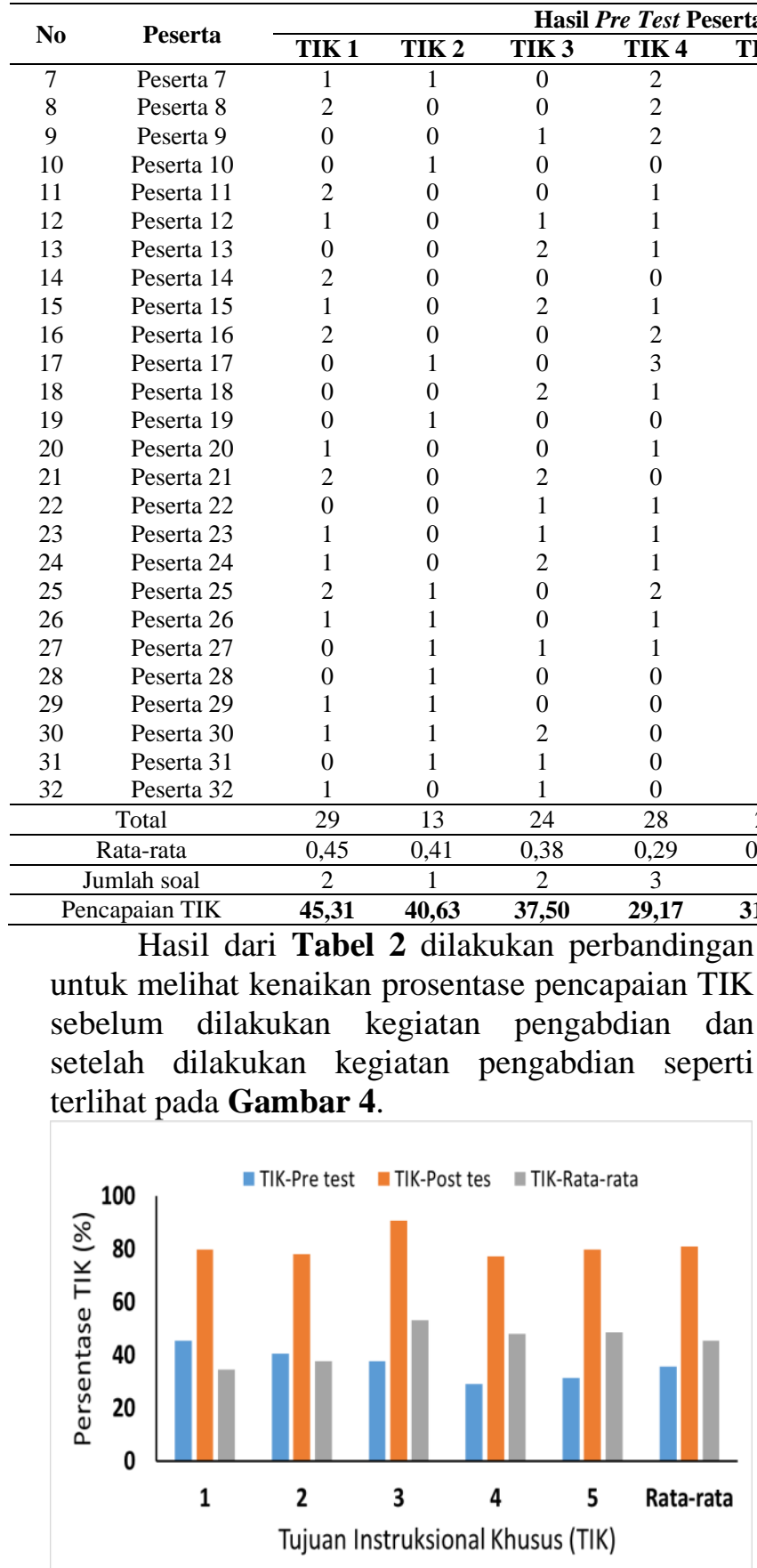

Gambar 4. Perbandingan pencapaian TIK sebelum dan setelah kegiatan pengabdian.

Berdasarkan Gambar 4 dapat dilihat bahwa pencapaian TIK sebelum diadakan kegiatan pengabdian adalah 35,63\%. Kemudian, setelah diadakan kegiatan pengabdian berubah menjadi $80,94 \%$. Oleh karena itu, dapat dikatakan bahwa masing-masing TIK mengalami kenaikan dengan rata-rata sebesar $45,31 \%$. Hal ini menunjukkan bahwa pengetahuan masyarakat tentang pembuatan lampu rumah tangga dengan menggunakan LED
Hasil Post Test Peserta

\begin{tabular}{|c|c|c|c|c|c|c|}
\hline SKOR & TIK 1 & TIK 2 & TIK 3 & TIK 4 & TIK 5 & SKOR \\
\hline 50 & 1 & 0 & 2 & 3 & 1 & 70 \\
\hline 40 & 2 & 1 & 1 & 3 & 2 & 90 \\
\hline 30 & 1 & 1 & 2 & 2 & 2 & 80 \\
\hline 10 & 2 & 1 & 2 & 3 & 1 & 90 \\
\hline 40 & 2 & 1 & 2 & 1 & 2 & 80 \\
\hline 40 & 1 & 0 & 2 & 3 & 1 & 70 \\
\hline 30 & 2 & 1 & 1 & 1 & 2 & 70 \\
\hline 40 & 1 & 1 & 2 & 2 & 2 & 80 \\
\hline 40 & 2 & 1 & 2 & 3 & 1 & 90 \\
\hline 50 & 2 & 1 & 2 & 1 & 2 & 80 \\
\hline 40 & 1 & 0 & 2 & 3 & 1 & 70 \\
\hline 30 & 2 & 1 & 1 & 3 & 2 & 90 \\
\hline 10 & 1 & 1 & 2 & 2 & 2 & 80 \\
\hline 40 & 2 & 1 & 2 & 3 & 1 & 90 \\
\hline 40 & 2 & 1 & 2 & 1 & 2 & 80 \\
\hline 30 & 1 & 0 & 2 & 3 & 1 & 70 \\
\hline 40 & 2 & 1 & 1 & 3 & 2 & 90 \\
\hline 40 & 1 & 1 & 2 & 2 & 2 & 80 \\
\hline 50 & 2 & 1 & 2 & 3 & 1 & 90 \\
\hline 40 & 2 & 1 & 2 & 1 & 2 & 80 \\
\hline 30 & 1 & 0 & 2 & 3 & 1 & 70 \\
\hline 10 & 2 & 1 & 1 & 3 & 2 & 90 \\
\hline 40 & 1 & 1 & 2 & 2 & 2 & 80 \\
\hline 40 & 2 & 1 & 2 & 3 & 1 & 90 \\
\hline 30 & 2 & 1 & 2 & 1 & 2 & 80 \\
\hline 40 & 1 & 0 & 2 & 3 & 1 & 70 \\
\hline 1140 & 51 & 25 & 58 & 64 & 51 & 2490 \\
\hline 0,36 & 0,80 & 0,78 & 0,91 & 0,77 & 0,80 & 0,81 \\
\hline 10 & 2 & 1 & 2 & 3 & 2 & 10 \\
\hline 35,63 & 79,69 & 78,13 & 90,63 & 77,08 & 79,69 & 80,94 \\
\hline
\end{tabular}

mengalami peningkatan secara signifikan sehingga secara keseluruhan tujuan awal dari kegiatan pengabdian ini telah tercapai dengan memuaskan. Peningkatan pengetahuan masyarakat Dusun Sakal Desa Tanjung Baru Kecamatan Merbau Mataram Kabupaten Lampung Selatan ini diharapkan dapat ditularkan kemasyarakat di desa lain secara umum sehingga dapat bersinergi dalam peningkatan kesejahteraan masyarakat.

\section{Kesimpulan}

Kegiatan pengabdian kepada masyarakat khususnya pembuatan lampu rumah tangga seperti ini perlu dikembangkan untuk meningkatkan minat wirausaha masyarakat pedesaan. Selain mendapatkan ilmu baru, masyarakat dianjurkan untuk melakukan bimbingan ke masyarakat desa lain agar dapat ilmu yang didapat lebih berguna dan bermanfaat bagi kemaslahatan masyarakat yang lebih banyak. Pencapaian TIK sebelum kegiatan pengabdian pembuatan lampu rumah tangga dengan teknik Joule Thief adalah 35,63\%. Pencapaian TIK setelah kegiatan pengabdian pembuatan lampu rumah tangga dengan teknik Joule Thief adalah $80,94 \%$. Terjadi peningkatan untuk masing-masing pencapaian TIK dengan ratarata sebesar $45,31 \%$. 


\section{Ucapan Terima Kasih}

Ucapan terima kasih terutama ditujukan kepada pemberi Lembaga Penelitian dan Pengabdian Kepada Masyarakat (LPPM) Universitas Lampung yang telah membiaya program pengabdian kepada masyarakat melalui skema hibah unggulan pengabdian dengan nomor kontrak 3574/UN26.21/PM/2019.

\section{Daftar Pustaka}

Ade, R., Dicky, R.P., dan Herlan, E.A.G. (2013). LED-based Smart Lamp with Multi Sensor Lampu Pintar Berbasis LED dengan Multi Sensor. Jurnal INKOM, 7, 67-73.

Arfiansyah, R., Ade, G.A., dan Dadang, L.H. 2012. Prakiraan Beban Puncak Jangka Panjang pada Sistem kelistrikan Indonesia Menggunakan Algoritma Adaptive Neuro_Fuzzy Inference System. Electrans Vol 11(2) 18-26.
Fithri, N. (2014). Pengembangan Emergency Lamp Dengan LED Luxeon Menggunakan Metode Quality Function Deployment (QED). Seminar Nasional Sains dan Teknologi 2014 Fakultas MESDM, 2010. Data Penggunaan Energi Listrik Indonesia. Mentri ESDM 2010

Jusman, 2018, BPS Kabupaten Lampung SelatanKecamatan Merbau Mataram dalam Angka, ISBN: 978-602-6818-74-4

PERMEN ESDM, 2010. Penetapan Tarif Tenaga Listrik yang disediakan oleh Perusahan Perseroan (Persero) PT Perusahaan Listrik Negara. Peraturan Mentri Energi dan Sumber Daya Mineral No 07 Tahun 2010.

Schubert, E.F. (2006) Light Emitting Diodes, Second edition. Cambridge University Press. ISBN 0521-86538-7

Suhardi, D. (2014). Prototipe Controller Lampu Penerangan LED (Light Emitting Diode) Independent Bertenaga Surya. Jurnal Gamma, $10,116-122$ 